\title{
Elusive Cardiac Angiosarcoma in a Young Pregnant Female: Rare Presentation With Fatal Outcome
}

\author{
Abdelkarim Waness ${ }^{\mathrm{a}, \mathrm{e}}$, Amal A. Batoon ${ }^{\mathrm{b}}$, Imran Mirzac ${ }^{\mathrm{c}}$, Wael Al Mahmeed
}

\begin{abstract}
Heart tumors are rare occurrences. They can present diagnostic challenges and severe complications especially in pregnant women. We report a rare case of angiosarcoma (AS) cordis of the right atrium in a young healthy pregnant female. Her diagnosis remained elusive for some time until development of advanced disease symptomatology. The diagnosis was unfortunately clinched when her tumor grew to be detected by imaging modalities. An emergency cesarean section was performed delivering a healthy baby. The patient was aggressively treated with chemotherapy to no avail. She passed away 2 months after her diagnosis was established. Only few cases of the occurrence of aggressive cardiac AS and human pregnancy are documented. The course of this disastrous combination is usually marked by severe complications, difficult therapeutic options and ultimately fast demise. Physicians need to be more aware of such diagnosis and diligently try to diagnose it as early as possible.
\end{abstract}

Keywords: Pregnancy; Pericardial effusion; Right atrium angiosarcoma; Echocardiography; Magnetic resonance imaging; Paclitaxel

\section{Introduction}

Cardiac tumors are rare occurrence. Their development however can be marred with complex symptomatology and severe complications. Angiosarcoma (AS) is a uniquely aggressive

Manuscript accepted for publication June 25, 2015

a Obstetrics and Gynecology Department, Sidra Medical and Research Center, Doha, Qatar

bDepartment of Medicine, Sheikh Khalifa Medical City, Abu Dhabi, United Arab Emirates

'Department of Pathology, Sheikh Khalifa Medical City, Abu Dhabi, United Arab Emirates

dDepartment of Cardiology, Sheikh Khalifa Medical City, Abu Dhabi, United Arab Emirates

${ }^{e}$ Corresponding Author: Abdelkarim Waness, Acute Care Medicine Division, Department of Obstetrics \& Gynecology, Sidra Medical \& Research Center, PO Box 26999, Doha, Qatar. Email: awaness@sidra.org

doi: http://dx.doi.org/10.14740/cr402w malignant neoplasm of endothelial cells. It can be encountered in various parts of the body including the heart. The discovery of this worrisome cardiac tumor in a pregnant female has been reported only in few documented instances.

\section{Case Report}

A G2P1 female in her thirties developed dyspnea while 18-week pregnant. She was taking prenatal vitamin, folic acid and occasional bronchodilator inhaler. Her vital signs were: temperature $36.3^{\circ} \mathrm{C}$, pulse $110 \mathrm{bpm}$, respiratory rate 22 per minute, BP 90/59 $\mathrm{mm} \mathrm{Hg}$, and oxygen saturation $97 \%$ on room air. On auscultation, she had distant heart sounds with pulsus paradoxus but no murmur or rub. The rest of her exam was normal including jugular venous pressure. Pertinent laboratory findings: hemoglobin $89 \mathrm{~g} / \mathrm{L}$, platelets: $223 \times 10^{9} / \mathrm{L}$, both anti-nuclear antibodies (ANA) and double-strand DNA antibodies (anti ds-DNA) testing were negative. The rest of her laboratory findings, including coagulation profile and thyroid stimulating hormone (TSH), were unremarkable. EKG showed sinus tachycardia. Transthoracic echocardiogram (TTE) (Fig. 1) demonstrated large pericardial effusion. With impending cardiac tamponade, the patient underwent pericardiocentesis and $800 \mathrm{~mL}$ of blood-stained fluid was removed. Cytopathologic and microbiologic examinations of the pericardial fluid showed multiple RBCs without detectable infectious, auto-immune, or malignant causes.

The initial working diagnosis was hemopericardium of unknown etiology. Two weeks post-discharge, a repeat TTE showed only a small pericardial effusion. A third TTE, done 6 weeks afterward, failed to show any apparent fluid collection. The patient unfortunately missed a third follow-up appointment.

At the 38th week of her pregnancy, the patient developed chest pain. Vital signs were: temperature $37.6{ }^{\circ} \mathrm{C}$, pulse 100 bpm, respiratory rate 19 per minute, BP $113 / 85 \mathrm{~mm} \mathrm{Hg}$, and oxygen saturation $98 \%$ on room air. Few crackles were detected on auscultation. Her abdomen was distended (appropriate for pregnancy) while the rest of the exam, including skin and lymph nodes, was negative. Laboratory tests included: hemoglobin $110 \mathrm{~g} / \mathrm{L}$, platelets $324 \times 10^{9} / \mathrm{L}$, and troponin 0.8 $\mathrm{ng} / \mathrm{mL}$. Electrocardiogram showed diffuse ST segment depression with $\mathrm{T}$ wave inversion. Trans-thoracic echocardiogram showed a fragile echo-dense mobile structure seen in a dilated 


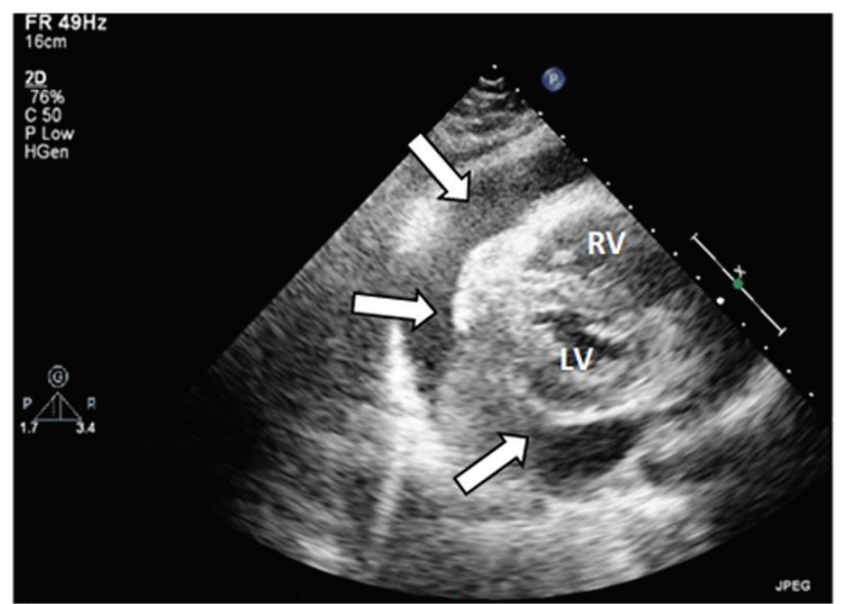

Figure 1. Large pericardial effusion (arrow). RV: right ventricle; LV: left ventricle.

right atrium (RA). A transesophageal echocardiography (TOE) confirmed the presence of a large right atrial mass (Fig. 2). Differential diagnoses shifted to possible RA thrombus or RA tumor. The patient underwent an emergency cesarean section delivering a healthy boy. Close uterine and placental inspections were unremarkable. Further evaluation, with computed tomography and magnetic resonance imaging (MRI) of the chest and abdomen, showed not only the presence of the right atrial mass but also multiple nodules scattered in both lungs and liver (Fig. 3). The patient underwent a biopsy of one hepatic lesion that showed moderate to poorly differentiated AS (Fig. 4).

The final diagnosis was metastatic cardiac AS to the lungs and liver. Chemotherapy with paclitaxel was initiated. Six weeks post-partum, a repeat TTE was done: it showed no change in the cardiac tumor size and no detectable pericardial effusion. Despite aggressive therapy, the patient succumbed to

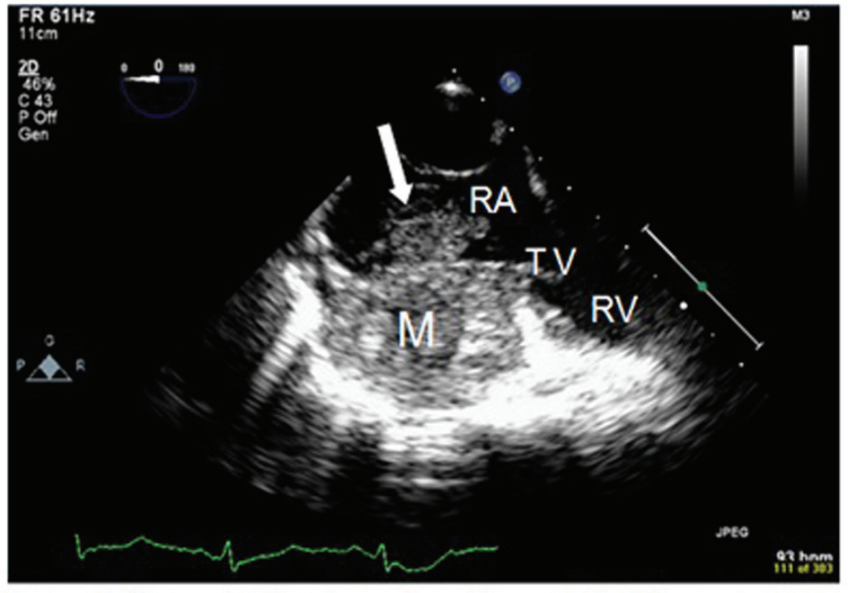

Figure 2. Transesophageal echocardiogram (TOE): transverse view of the right chambers. There is a large firm infiltrating mass $(M)$ in the right atrium (RA), with a propagation (arrow) within the right atrial cavity. RA right atrium; TV: tricuspide valve; RV: right ventricle.

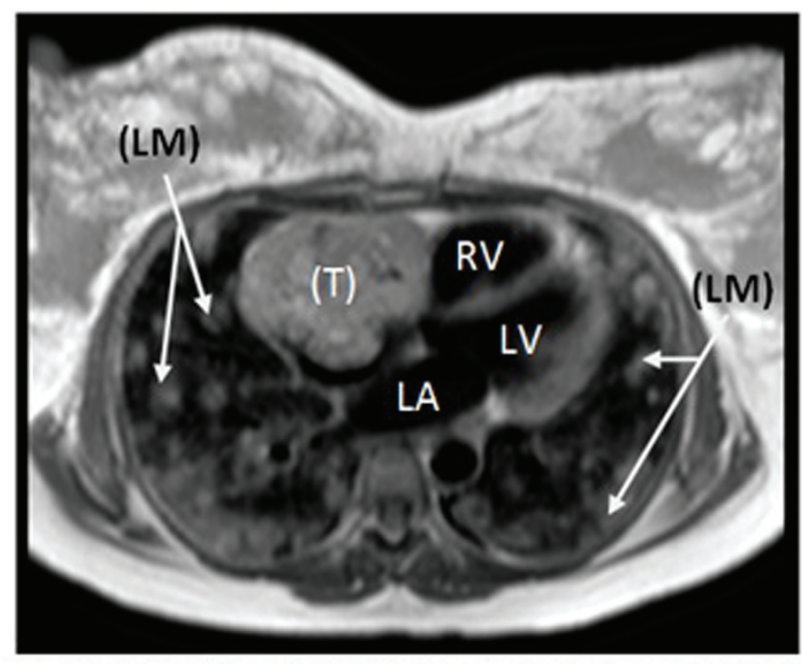

Figure 3. Cardiac MRI revealing large irregular tumor $(T)$ occupying most of the RA, with numerous bilateral lung metastases (LM). RV: right ventricle; LA: left atrium; LV: left ventricle.

death 3 months after establishing her diagnosis.

\section{Discussion}

ASs are rare aggressive malignant tumors emanating from blood vessels' endothelial cells. Genetic and congenital factors seem to play a role in the genesis of AS $[1,2]$. Radiotherapy and vinyl chloride are also believed to contribute to their development [3, 4]. Immunohistological studies have identified factors such as

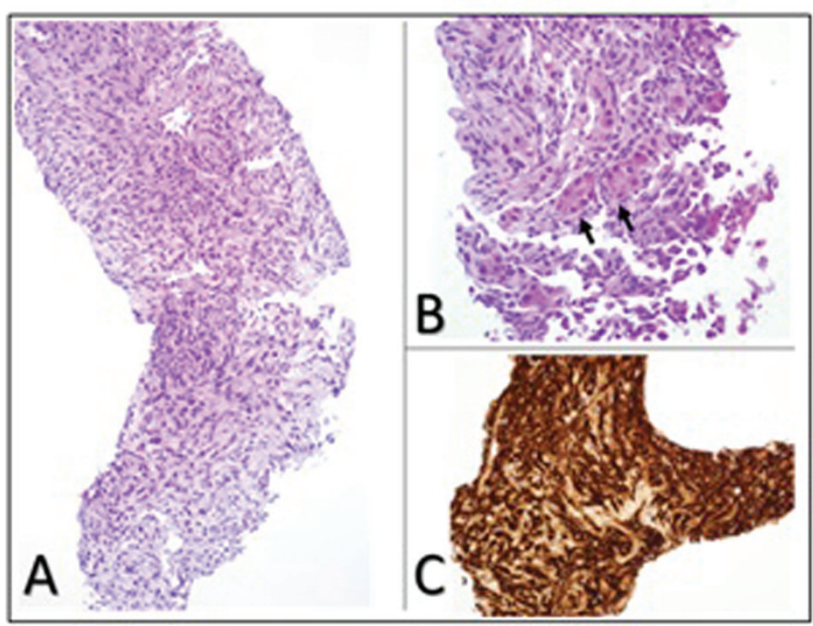

Figure 4. Liver biopsy showing (A) photomicrograph of moderate to poorly differentiated angiosarcoma with dense clumps of plump and spindle shaped, anaplastic cells focally showing slit-like vascular lumens (original magnification, $\times 200$ ); (B) entrapped hepatocytes (arrows) within the tumor (original magnification, $\times 400$ ); (C) immunohistochemical staining for the endothelial marker CD34 demonstrating the endothelial origin of the neoplastic cells. 
protein kinase $\mathrm{p}$-AKT and the over-expression of vascular endothelial growth factors in the pathogenesis of these tumors [5].

The prevalence of primary cardiac tumors is estimated at $0.01 \%$ in post-portem studies [6]. The spectrum of primary cardiac tumors is dominated by benign myxomas. It is reported that $25 \%$ of all cardiac tumors are highly aggressive ASs [7]. While myxomas have predilection for the left atrium (LA), AS seem to favor the RA. In a large series of 242 heart tumor cases, $\mathrm{Yu}$ and colleagues confirmed this predilection: four out of seven AS $(57 \%)$ cases originated in the RA [8]. Another 10-year single center experience of 24 cardiac sarcomas pointed to this predilection: 10 out of $24(41.6 \%)$ cases were AS, and all of them $(100 \%)$ originated in the RA [9]. The mean age for AS in this series was 42.2 years. The occurrence of cardiac AS in younger population is documented by Hamidi and colleagues [10]. There is no apparent gender predilection for these tumors however.

Coincidental occurrence of primary AS cordis with pregnancy is extremely unusual. Only few cases, from 1969 to 2012, were reported in the medical literature [11-15].

Our unfortunate patient had her tumor also originating in the RA. She presented a challenging diagnostic dilemma from the beginning. She had two different clinical and echocardiographic presentations. Initially, she developed a picture of impending cardiac tamponade that was relieved by pericardiocentesis of blood-stained fluid. Two subsequent TTEs gave the false impression of a "possibly benign pericardial effusion". It took only four short months for this patient's tumor to herald its aggressive presence in the heart, lungs and liver.

During pregnancy, the placenta secretes a VEGF homolog called the placenta growth factors (PlGFs). PlGF-1 acts as a natural antagonist of VEGF when both factors are simultaneously synthesized in murine fibrosarcoma cells. The exact role(s) of PlGF in cancer growth and dissemination remain to be fully understood however [16].

As illustrated in this case, diagnosing primary AS cordis at an early stage can be very challenging [17]. These tumors usually have late, dramatic and devastating presentation with a variety of constitutional symptoms such as cardiac chamber flow obstruction, valvular dysfunction, cardiac arrhythmias, pericardial effusion, and embolic phenomena [18]. Complications might include: syncope [19], superior vena cava syndrome [20], spontaneous right atrial rupture resulting in cardiac tamponade [21], and even fistulization between the RA and the right coronary artery (RCA) causing hemopericardium [22]. Sudden death remains the ultimate devastating presentation of cardiac AS [23]. Hematogenous embolic dissemination of cardiac AS can originate from either the right or the left-side cardiac chambers. Metastatic lesions were reported in lungs [24], liver [25], brain [26], and even within the cervical spine [27].

Physical assessment, electrocardiography, and chest X-ray usually provide limited and non-specific findings. Conventional two-dimentional TTE remains the initial investigational tool used to assess cardiac symptoms. It has its limitations however such as narrow examination windows and operator dependancy. TOE, on the other hand, can provide better access to cardiac structures but it needs special arrangements, a trained cardiologist, and carries some morbidity. Both TTE and TOE offer an excellent diagnostic sensitivities of $93.3 \%$ and $96.8 \%$ respectively for primary cardiac tumors [28]. Some authors advocate the use of real-time three-dimentional echocardiography for better structural visualization of cardiac AS and their surrounding structures [29].

Computed tomography, especially multi-slice computed tomography (MSCT), is another important radiological tool in the visualization of both primary cardiac AS and their metastatic lesions. Some tumors can be missed however [30]. Some authors reported using a combination: MSCT and positron emission tomography (PET) in order to improve the diagnostic yield and determine the malignant nature of intra-cardiac AS [31]. MRI of the heart has become the reference imaging method for evaluation of suspected cardiac tumors. Mohrs et al reported $100 \%$ sensitivity, $100 \%$ specificity, $100 \%$ positive and negative predictive values for hyper-perfused and for iso-perfused primary cardiac lesions [32]. Tissue biopsy remains the diagnostic gold standard. It must be carried by an experienced interventionalist because of the numerous possible complications (cardiac perforation, arrhythmias, embolic events, etc.).

The battery of therapeutic interventions for primary cardiac tumors keep on growing. At an early stage, radical surgical resection remains essential for improving survival rate of primary cardiac AS. Patients who underwent surgery had a median survival of 12 months whereas those who did not undergo surgery had a median survival of only 1 month [10]. Depending on the location of the tumor within the heart, surgical intervention often requires atrial or ventricular reconstruction $[33,34]$. Some specialized centers tried heart transplantation or combined heart and lung transplantation for non-resectable primary cardiac sarcoma $[35,36]$. The extremely high recurrence of metastatic disease and the prohibitive costs of these surgeries limit their usefulness, however.

Chemotherapy, with different regimen, is often used for the treatment of sarcomas $[2,20,37,38]$. The role of radiation therapy has not been established as for malignant cardiac tumors [39]. Finally, some authors propose using the tumor marker CA125 as a good indicator for therapeutic efficacy in the treatment of AS [40].

Despite all therapeutic interventions, primary cardiac ASs have a notoriously grim outcome with a median overall survival ranging from 6 to 14 months [10, 41, 42].

\section{Conclusions}

The coincidental and disastrous occurrence of primary cardiac AS and pregnancy is extremely rare. The physiopathology behind this dreadful combination is not fully understood. Further research into this field is warranted. The clinical presentation can be insidious and challenging. Physicians are encouraged to have a high index of suspicion and vigilance in order to diagnose theses aggressive tumors. Despite urgent multi-faceted therapeutic interventions, AS cordis still has an unrelenting down-spiral course with a dismal outcome.

\section{Acknowledgement}

We would like to thank Mr. Ehab Jaradat for his assistance 
with figures.

\section{Disclosure Statement}

No competing financial interests exist.

\section{References}

1. Keeling IM, Ploner F, Rigler B. Familial cardiac angiosarcoma. Ann Thorac Surg. 2006;82(4):1576.

2. Good AB, Nascimento A, Welker KM, Arndt CA. Congenital angiosarcoma with transient response to paclitaxel. J Pediatr Hematol Oncol. 2008;30(6):451-453.

3. Kunkel T, Mylonas I, Mayr D, Friese K, Sommer HL. Recurrence of secondary angiosarcoma in a patient with post-radiated breast for breast cancer. Arch Gynecol Obstet. 2008;278(5):497-501.

4. Infante PF, Petty SE, Groth DH, Markowitz G, Rosner D. Vinyl chloride propellant in hair spray and angiosarcoma of the liver among hairdressers and barbers: case reports. Int J Occup Environ Health. 2009;15(1):36-42.

5. Lahat G, Dhuka AR, Hallevi H, Xiao L, Zou C, Smith KD, Phung TL, et al. Angiosarcoma: clinical and molecular insights. Ann Surg. 2010;251(6):1098-1106.

6. Amonkar GP, Deshpande JR. Cardiac angiosarcoma. Cardiovasc Pathol. 2006;15(1):57-58.

7. Sheppard MN, Mohiaddin R. Tumors of the heart. Future Cardiol. 2010;6(2):181-193.

8. Yu K, Liu Y, Wang H, Hu S, Long C. Epidemiological and pathological characteristics of cardiac tumors: a clinical study of 242 cases. Interact Cardiovasc Thorac Surg. 2007;6(5):636-639.

9. Kim CH, Dancer JY, Coffey D, Zhai QJ, Reardon M, Ayala AG, Ro JY. Clinicopathologic study of 24 patients with primary cardiac sarcomas: a 10-year single institution experience. Hum Pathol. 2008;39(6):933-938.

10. Hamidi M, Moody JS, Weigel TL, Kozak KR. Primary cardiac sarcoma. Ann Thorac Surg. 2010;90(1):176-181.

11. Lebreuil G, Bonerandi J, Yassine M, Payan H. [Angiosarcomas of the heart and pericardium. Apropos of an anatomo-clinical case]. Arch Anat Pathol (Paris). 1969;17(1):A40-46.

12. Simon BC, Funck R, Drude L, Bohle RM, Reichart B, Maisch B. [Malignant angiosarcoma of the right atrium in pregnancy. Diagnostic and therapeutic problems]. Herz. 1994;19(3):166-170.

13. Azimi NA, Selter JG, Abott JD, Cabin HS, Hutner A, Copel J, Setaro JF. Angiosarcoma in a pregnant woman presenting with pericardial tamponade--a case report and review of the literature. Angiology. 2006;57(2):251-257.

14. Saraiva F, Antunes M, Providencia LA. Cardiac angiosarcoma in a pregnant woman: a case report and review of the literature. Acta Cardiol. 2012;67(6):727-731.

15. Valeeva RM, Gaisin IR, Shilina LV, Vavilkina Zh V, Smirnova ES, Nikolaeva NB, Kir'ianov NA. [Cardiac angiosarcoma in a pregnant women]. Kardiologiia. 2012;52(6):93-95.
16. Eriksson A, Cao R, Pawliuk R, Berg SM, Tsang M, Zhou $\mathrm{D}$, Fleet $\mathrm{C}$, et al. Placenta growth factor-1 antagonizes VEGF-induced angiogenesis and tumor growth by the formation of functionally inactive PlGF-1/VEGF heterodimers. Cancer Cell. 2002;1(1):99-108.

17. El-Osta HE, Yammine YS, Chehab BM, Fields AS, Moore DF, Jr., Mattar BI. Unexplained hemopericardium as a presenting feature of primary cardiac angiosarcoma: a case report and a review of the diagnostic dilemma. $\mathrm{J}$ Thorac Oncol. 2008;3(7):800-802.

18. Murinello A, Mendonca P, Abreu A, Santos AL, Roquete J, Pinto E, Alpendra J, et al. Cardiac angiosarcoma--a review. Rev Port Cardiol. 2007;26(5):577-584.

19. Nayar S, Nayar PG, Cherian K. Angiosarcoma presenting as syncope. Asian Cardiovasc Thorac Ann. 2008;16(2):154-156.

20. Ishibashi N, Mitachi Y, Sugawara S, Shinozaki S, Miura M, Fukuju T, Katahira Y, et al. [A case of cardiac angiosarcoma successfully treated with docetaxel]. Gan To Kagaku Ryoho. 2007;34(11):1849-1852.

21. Corso RB, Kraychete N, Nardeli S, Moitinho R, Ourives C, Silva RM, Pereira RE. Spontaneous rupture of a right atrial angiosarcoma and cardiac tamponade. Arq Bras Cardiol. 2003;81(6):611-613, 608-610.

22. Yoshitake I, Hata M, Sezai A, Niino T, Unosawa S, Shimura K, Kasamaki Y, et al. Cardiac angiosarcoma with cardiac tamponade diagnosed as a ruptured aneurysm of the sinus valsalva. Jpn J Clin Oncol. 2009;39(9):612-615.

23. Cina SJ, Smialek JE, Burke AP, Virmani R, Hutchins GM. Primary cardiac tumors causing sudden death: a review of the literature. Am J Forensic Med Pathol. 1996;17(4):271281.

24. Ebi N, Yamamoto H, Sakai J, Sugahara K, Arimura H, Nakanishi K. Angiosarcoma of the heart presenting as fatal pulmonary hemorrhage. Intern Med. 1997;36(3):191193.

25. Mahdhaoui A, Bouraoui H, Cheniour M, Trimech B, Mesghani S, Majdoub M, Hayouni A, et al. [Right atrium angiosarcoma disclosed by alveolar hemorrhage]. Rev Med Suisse Romande. 2004;124(2):115-116.

26. Ikeya E, Taguchi J, Yamaguchi M, Shibuya M, Kanabuchi K. Primary cardiac angiosarcoma: presenting with cardiac tamponade followed by cerebral hemorrhage with brain metastases. Jpn J Thorac Cardiovasc Surg. 2006;54(12):528-531.

27. Shapiro S, Scott J, Kaufman K. Metastatic cardiac angiosarcoma of the cervical spine. Case report. Spine (Phila $\mathrm{Pa}$ 1976). 1999;24(11):1156-1158.

28. Meng Q, Lai H, Lima J, Tong W, Qian Y, Lai S. Echocardiographic and pathologic characteristics of primary cardiac tumors: a study of 149 cases. Int J Cardiol. 2002;84(1):69-75.

29. Yang HS, Sengupta S, Umland MM, Chandrasekaran K, Mookadam F. Primary cardiac angiosarcoma evaluated with contrast two-dimensional and real-time threedimensional echocardiography. Eur J Echocardiogr. 2008;9(5):733-738.

30. Inoko M, Iga K, Kyo K, Kondo H, Tamura T, Izumi C, Kitagichi S, et al. Primary cardiac angiosarcoma detected 
by magnetic resonance imaging but not by computed tomography. Intern Med. 2001;40(5):391-395.

31. Hori Y, Funabashi N, Miyauchi H, Nakagawa K, Shimura $\mathrm{H}$, Miyazaki M, Kozono H, et al. Angiosarcoma in the right atria demonstrated by fusion images of multislice computed tomography and positron emission tomography using F-18 Fluoro-Deoxyglucose. Int J Cardiol. 2007;123(1):e15-17.

32. Mohrs OK, Voigtlaender T, Petersen SE, Zander M, Schulze T, Pottmeyer A, Kauczor HU. First experiences with contrast-enhanced first-pass MR perfusion imaging in patients with primary, benign cardiac masses and tumour-like lesions. Eur Radiol. 2008;18(8):1617-1624.

33. Pigott C, Welker M, Khosla P, Higgins RS. Improved outcome with multimodality therapy in primary cardiac angiosarcoma. Nat Clin Pract Oncol. 2008;5(2):112-115.

34. Chachques JC, Argyriadis PG, Latremouille C, D'Attellis N, Fornes P, Bruneval P, Couetil JP, et al. Cardiomyoplasty: ventricular reconstruction after tumor resection. J Thorac Cardiovasc Surg. 2002;123(5):889-894.

35. Uberfuhr P, Meiser B, Fuchs A, Schulze C, Reichenspurner H, Falk M, Weiss M, et al. Heart transplantation: an approach to treating primary cardiac sarcoma? J Heart Lung Transplant. 2002;21(10):1135-1139.

36. Talbot SM, Taub RN, Keohan ML, Edwards N, Galantowicz ME, Schulman LL. Combined heart and lung transplantation for unresectable primary cardiac sarcoma. J Thorac Cardiovasc Surg. 2002;124(6):1145-1148.
37. Asmane I, Litique V, Heymann S, Marcellin L, Metivier AC, Duclos B, Bergerat JP, et al. Adriamycin, cisplatin, ifosfamide and paclitaxel combination as front-line chemotherapy for locally advanced and metastatic angiosarcoma. Analysis of three case reports and review of the literature. Anticancer Res. 2008;28(5B):3041-3045.

38. Maurel J, Lopez-Pousa A, de Las Penas R, Fra J, Martin J, Cruz J, Casado A, et al. Efficacy of sequential high-dose doxorubicin and ifosfamide compared with standarddose doxorubicin in patients with advanced soft tissue sarcoma: an open-label randomized phase II study of the Spanish group for research on sarcomas. J Clin Oncol. 2009;27(11):1893-1898.

39. Neragi-Miandoab S, Kim J, Vlahakes GJ. Malignant tumours of the heart: a review of tumour type, diagnosis and therapy. Clin Oncol (R Coll Radiol). 2007;19(10):748-756.

40. Yanada M, Shimada J, Ito K, Terauchi K, Shimomura M. [Cardiac angiosarcoma with diagnostic difficulty]. Kyobu Geka. 2007;60(13):1148-1151.

41. Truong PT, Jones SO, Martens B, Alexander C, Paquette M, Joe H, Hart J, et al. Treatment and outcomes in adult patients with primary cardiac sarcoma: the British Columbia Cancer Agency experience. Ann Surg Oncol. 2009;16(12):3358-3365.

42. Kamiya H, Yasuda T, Nagamine H, Sakakibara N, Nishida S, Kawasuji M, Watanabe G. Surgical treatment of primary cardiac tumors: 28 years' experience in Kanazawa University Hospital. Jpn Circ J. 2001;65(4):315-319. 